\title{
Solar Radiation as Alternative Power Supply for Electricity Generation in Nigeria
}

\author{
Ogbaka, D.T. ${ }^{1}$ \\ ${ }^{1}$ Department of Pure and \\ Applied Physics, Faculty \\ of Science. Adamawa \\ State University, Mubi. \\ Adamawa State, Nigeria
}

\author{
Aminu C. M. ${ }^{2}$ \\ ${ }^{2}$ Department of Electrical \\ and Electronics \\ Engineering Technology, \\ Gombe State Polytechnic, \\ Bajoga, Nigeria
}

\author{
Umar S.B ${ }^{2}$ \\ ${ }^{2}$ Department of Electrical \\ and Electronics \\ Engineering Technology, \\ Gombe State Polytechnic, \\ Bajoga, Nigeria
}

\begin{abstract}
In this study, the Angstrom-Prescott regression equation which has been used to estimate the monthly average daily solar radiation on a horizontal surface was used. The values of the regression coefficients $\mathrm{a}$ and $\mathrm{b}$ as 0.34 and 0.42 were determine. The statistical error estimations such as RMSE and MBE used to test the correlation between the measured global solar radiation and the calculated global solar radiation. The RMSE was found to be 0.05 as low as expected and the MBE was also found to be 0.015 . Global radiations obtained in this study are higher with mean value of $23.60 \mathrm{MJm}^{-2}$ and the measured value $23.48 \mathrm{MJm}^{-2}$ which shows the presence of high global solar energy potential in Maiduguri, Nigeria. The global solar radiation intensity predicted in this study can also be utilized in design, analysis and performance estimation of solar energy systems, which is gaining significant attention in Nigeria and the world at large.
\end{abstract}

Keyword: Global Solar Radiation, Sunshine Hours, Regression Constants, Electricity.

\section{INTRODUCTION}

Energy is a vital and important necessity for all earthly processes. The socio-economic activities of modern society revolved around the hub of energy availability. The 1973 oil crises, chaos caused by the Arab oil embargo, in western countries brought a sudden global realization to use renewable energy resources such as solar energy, hydropower, wind energy, wave energy, biomass and biofuels (Animalu and Adekola, 2002). This campaign for using renewable energy resources is becoming stronger today because of the finite nature of fossil fuel energy resources as well as the greenhouse gases emission which many scientists believe cause global warming. (Nwoke et al., 2008). Effective applications of renewable energy resources to augment energy supply from fossil fuel energy resources (using cleaner for fossil fuel technologies) will enhance availability of energy with minimum environmental effect.

Solar energy can be defined as the energy obtains from the sun, which is electro magnetic in nature covering all wavelength of the sun (Ilenikhena, et al., 2008). The sun is about $1.4 \mathrm{x}$ $10^{14} \mathrm{~m}$ in diameter emits its energy at the rate of about $3.8 \times 10^{23} \mathrm{Js}^{-1}$ of solar energy of which about $1.7 \times 10^{14} \mathrm{Js}^{-1}$ reaches the earth, warming the ground, ocean ,atmosphere and drilling the photosynthesis process that maintain the biological life . Most of the solar radiation is confined within the wavelength of 3.8 and $0.7 \mathrm{~nm}$. Solar energy occupies one of the most important places as many among the various possible alternative energy sources it is the only option left to be developed and utilized. It is an inexhaustible source, potentially capable of meeting a significant portion of the world future energy needs with a minimum of adverse environment consequences. The availability of solar energy has to be considered. The region with greater solar insolation on the earth's surface lies between latitude $20^{\circ}-30^{\circ} \mathrm{N}$ and south of the equator (Ilenikhena and Mordi, 2005). Therefore, the availability of solar energy over the earth surface is not uniform (Eze, 2004). It has been confirmed that Nigeria receives $9.12 \times 10 \mathrm{~s}$ $\mathrm{MWm}^{-2}$ of energy per day from the sun. And if solar energy appliance with $5 \%$ efficiency is used to only $1 \%$ of the country surface area then $2.45 \mathrm{x}$ $106 \mathrm{nJs}^{-1}$ and electrical energy is equivalent to 4.66 million barrels of oil per day (Oparaku, 2007).

In Nigeria, the availability of a reliable power supply is still very minimal because the major source of electricity in the country is the hydropower, which is usually restricted to the generation of shaft power from falling water. The main hydropower station constructed across river Niger at Kainji is designed and managed by the different Power Distribution Companies in Nigeria to deliver the required energy for the expanding Nigeria industry. But these companies have been noted for unreliable power supply characterized by low voltage and incessant power cuts often without 
warning or even apologies to consumers (Ileoje, 1997).

This is the major reason among many others prompted the emergence of study. This erratic nature of electric power supply has caused the economy to fall, unless it is supplemented. The way out of this lies in the use of renewable source of energy for power generation, as they contain enormous, largely untapped and sustained opportunity for meeting the energy need as they are environmentally friendly as they do not contribute harmful and toxic emission to it. The solar energy is one of the cleanest and most environmentally sources of energy capable of generating a high amount of electricity. The aim of this study is to assess solar radiation as an alternative energy for electricity generation in Maiduguri.

\section{MATERIALS AND METHOD}

Maiduguri is the capital city of Borno state and one of the largest cities of Nigeria, situated in north eastern part of the country. The latitude of Maiduguri is $11.85^{\circ} \mathrm{N}$, longitude is $13.08^{\circ} \mathrm{E}$ with altitude of $354 \mathrm{~m}$. The following parameters were collected from the Archives of Nigerian meteorological Agency, National Weather Forecasting and Climate Research Centre Abuja for the period of ten years, from two thousand and one to two thousand and ten (2001-2010). Mainly daily global solar radiation and Sunshine hour.

The Angstrom- Prescott regression equation which has been used to estimate the monthly average daily solar radiation on a horizontal surface in Nigeria or other places is given as (Angstrom, 1924; Prescott, 1940):

$\frac{\bar{H}_{m}}{\bar{H}_{o}}=\left[a+b \frac{\bar{S}}{\bar{S}_{o}}\right]$

$\bar{H}_{m}$ is daily mean values of global radiation (MJm ${ }^{2}$ day $\left.^{-1}\right), \bar{S}_{o}$ the daily average value of day length, and ' $a$ ' and ' $b$ ' values are known as Angstrom constants and they are empirical. $\bar{H}_{o}$ is daily mean values of extraterrestrial radiation $\left(\mathrm{MJm}^{-2} \mathrm{day}^{-1}\right)$, calculated using equation (2) as described by (Neuwirth, 1980; Duffie, and Beckman, 1991).

$\bar{H}_{o}=\frac{24 \times 3,600}{\pi} I_{s c} E_{o}\left[\cos (\varphi) \cos (\delta) \sin \left(\omega_{s}\right)+\right.$

$\left.\frac{\pi \omega_{s}}{180} \sin (\varphi) \sin (\delta)\right]$

$I_{s c}=\frac{1,367 \times 3,600}{1,000,000} M^{-2} \mathrm{day}^{-1}$

$\mathrm{I}_{\mathrm{s}}$ the solar constant, The units in $\mathrm{kWhm}^{-2} \mathrm{day}^{-1}$ $\mathrm{E}_{\mathrm{o}}$ represents the eccentricity correction, and described using Eq. (3.4) in Eq. 3.2

$E_{o}=1+0.033 \cos \frac{360 n_{d}}{365}$

$\mathrm{n}_{\mathrm{d}}$ is the day number of the year /Julian day (1 Jan, $\mathrm{n}_{\mathrm{d}}=1$ and $31^{\text {st }}$ December, $\left.\mathrm{n}_{\mathrm{d}}=365\right), \varphi$ is the latitude of the site, $\delta$ the solar declination and, $\omega_{\mathrm{s}}$, the mean sunset hour angle for the given month. The solar declination $(\delta)$ and the mean sunset hour angle $\left(\omega_{\mathrm{s}}\right)$ can be calculated: $\delta=23.45 \sin 360 \frac{284+n_{d}}{265}$
$\omega_{s}=\cos ^{-1}(-\tan \varphi \tan \delta)$

For a given day, the maximum possible values of day length can be computed by using Cooper's formula (Cooper, 1969):

$\bar{S}_{o}=\frac{2}{15} \cos ^{-1}(-\tan \varphi \tan \delta)$

\section{(7)}

Tiwari and Sangeeta (1997), computed regression coefficient $a$ and $b$ from the calculated monthly average global solar radiation has been obtained from the relationship given as:

$\mathrm{a}=-0.110+0.235 \cos \varphi+0.323\left(\frac{\bar{s}}{\bar{s}_{o}}\right)$
$\mathrm{b}=1.449-0.553 \cos \varphi-0.694\left(\frac{\bar{s}}{\bar{s}_{o}}\right)$

The performance of the models was evaluated on the basis of the following statistical error tests: Root Mean Square Error (RMSE) and Mean Bias Error (MBE). It is recommended that a zero value for MBE is ideal while a low RMSE and low MPE are desirable (Nguyen and Pryor, 1997):

$R M S E=\left[\frac{1}{n} \sum_{i=1}^{n}\left(H_{i, m}-H_{i, c}\right)^{2}\right]^{\frac{1}{2}}$
$M B E=\frac{1}{n} \sum^{n}\left(H_{i, m}-H_{i, c}\right)$

$M B E=\frac{1}{n} \sum_{i=1}^{n}\left(H_{i, m}-H_{i, c}\right)$

Where $\mathrm{H}_{\mathrm{i}, \mathrm{m}}$ is the ith measured value, $\mathrm{H}_{\mathrm{i}, \mathrm{c}}$ is the ith calculated value of solar radiation and $\mathrm{N}$ is the total number of observations.

\section{RESULTS AND DISCUSSION}

Table 1 shows the values of measured monthly mean daily sunshine hours $\bar{S}$, day length $\bar{S}_{o}$, global solar radiation on a horizontal surface $\bar{H}_{m}$, extraterrestrial solar radiation on a horizontal surface $\bar{H}_{o}$, as well as the clearness index $\mathrm{K}_{\mathrm{T}}$.

Table 1: Meteorological parameters for Maiduguri from (2001-2010).

\begin{tabular}{|c|c|c|c|c|c|c|}
\hline $\begin{array}{c}\text { Month } \\
\mathrm{S}\end{array}$ & $\bar{S}(\mathrm{hr})$ & $\bar{S}_{o}(\mathrm{hr})$ & $\bar{S} / \bar{S}_{o}$ & $\bar{H}_{m}$ & $\bar{H}_{o}$ & $\left(\bar{H}_{m} / \bar{H}_{o}\right)$ \\
\hline Jan. & 9.0 & 11.51 & 0.78 & 17.3 & 32.3 & 0.54 \\
\hline Feb. & 9.7 & 11.76 & 0.73 & 21.5 & 34.7 & 0.62 \\
\hline Mar. & 8.1 & 12.09 & 0.76 & 28.4 & 36.9 & 0.77 \\
\hline Apr. & 8.3 & 12.40 & 0.75 & 26.8 & 37.9 & 0.71 \\
\hline May & 8.9 & 12.63 & 0.71 & 28.1 & 37.4 & 0.75 \\
\hline Jun. & 8.4 & 12.67 & 0.66 & 25.3 & 36.7 & 0.69 \\
\hline Jul. & 6.6 & 12.51 & 0.53 & 24.2 & 36.8 & 0.66 \\
\hline Aug. & 6.3 & 12.23 & 0.52 & 21.5 & 37.4 & 0.57 \\
\hline Sep. & 7.5 & 11.89 & 0.63 & 23.4 & 37.1 & 0.63 \\
\hline Oct. & 8.7 & 11.59 & 0.75 & 28.3 & 35.3 & 0.80 \\
\hline Nov. & 10.0 & 11.40 & 0.88 & 24.8 & $\begin{array}{c}32.7 \\
n\end{array}$ & 0.76 \\
\hline
\end{tabular}




\begin{tabular}{|l|l|l|l|l|l|l|}
\hline Dec. & 10.3 & 11.37 & 0.91 & 20.0 & 31.4 & 0.64 \\
\hline
\end{tabular}

Table 2: Measured and calculated values of Solar Radiation for Maiduguri.

\begin{tabular}{|c|c|c|c|c|c|}
\hline Months & $\bar{S}$ & $\bar{S}_{o}$ & $\bar{H}_{m}$ & $\bar{H}_{o}$ & $\bar{H}_{e}$ \\
\hline Jan. & 9.0 & 11.51 & 17.3 & 32.32 & 21.32 \\
\hline Feb. & 9.7 & 11.76 & 21.5 & 34.71 & 23.61 \\
\hline Mar. & 8.1 & 12.09 & 28.4 & 36.99 & 26.58 \\
\hline Apr. & 8.3 & 12.40 & 26.8 & 37.91 & 24.96 \\
\hline May & 8.9 & 12.63 & 28.1 & 37.37 & 27.54 \\
\hline Jun. & 8.4 & 12.67 & 25.3 & 36.74 & 23.43 \\
\hline Jul. & 6.6 & 12.51 & 24.2 & 36.89 & 23.54 \\
\hline Aug. & 6.3 & 12.23 & 21.5 & 37.46 & 19.62 \\
\hline Sep. & 7.5 & 11.89 & 23.4 & 37.16 & 20.23 \\
\hline Oct. & 8.7 & 11.59 & 28.3 & 35.35 & 26.75 \\
\hline Nov. & 10.0 & 11.40 & 24.8 & 32.79 & 23.97 \\
\hline Dec. & 10.3 & 11.37 & 20.0 & 31.42 & 22.40 \\
\hline
\end{tabular}

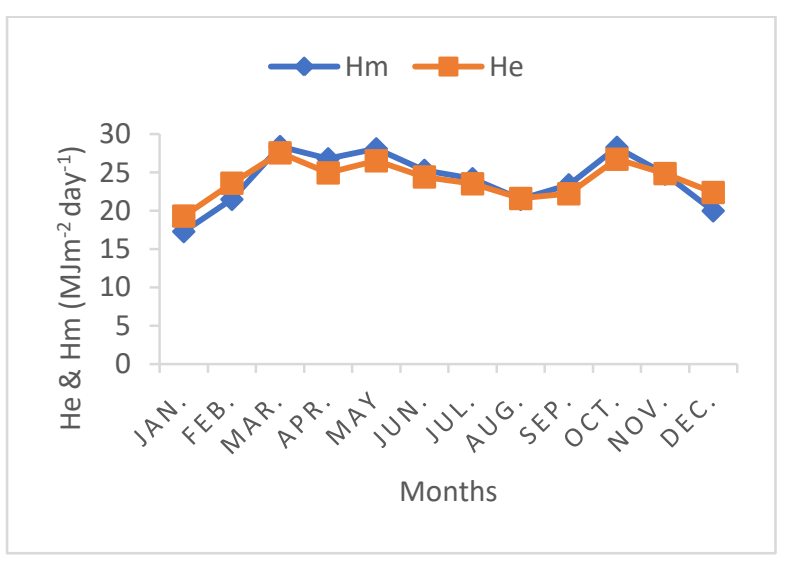

Fig. 1. Clearness index and Sunshine hours.

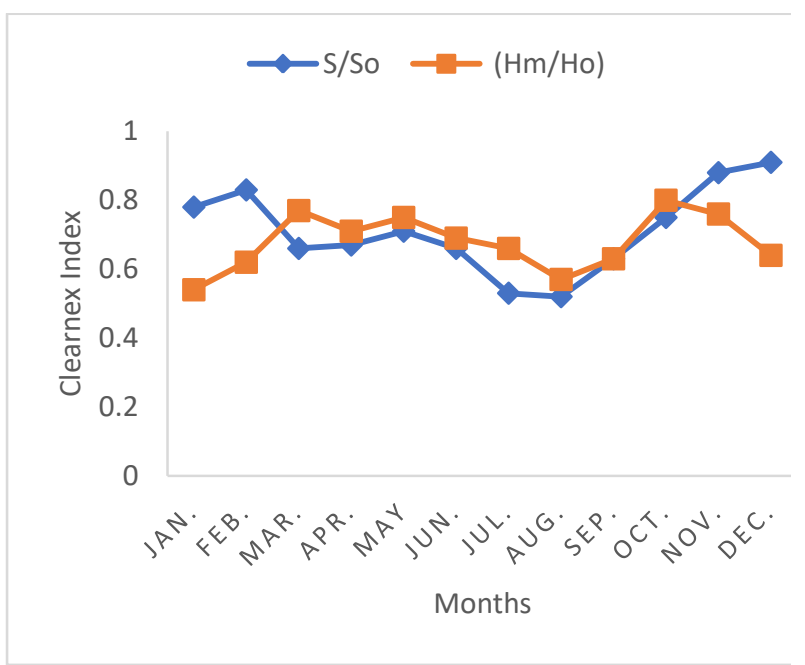

Fig. 2: Comparison between measured and predicted Solar Radiation
From Table 2, it is observed that the monthly global solar radiation is not uniform throughout the period of study. Peak solar radiation is observed in the months of March, April and May to be 26.58 $\mathrm{MJm}^{-2} \mathrm{day}^{-1}$, $24.96 \mathrm{MJm}^{-2} \mathrm{day}^{-1}$, and 27.54 $\mathrm{MJm}^{-}$ ${ }^{2} \mathrm{day}^{-1}$. On the other hand, the months of August and September recorded least amount of solar radiation average values of $19.62 \mathrm{MJm}^{-2} \mathrm{day}^{-1}$ and $20.23 \mathrm{MJm}^{-2}$ day $^{-1}$ respectively. This is as a result of the peak period of the cloud cover in Maiduguri due to the rainy season. In general, higher value of solar radiation is obtained in dry season than wet season. The relationship between the relative sunshine duration $\left(\frac{S}{S_{o}}\right)$, and clear sky index $\left(\mathrm{K}_{\mathrm{T}}\right)$ or $\left(\frac{H_{m}}{H_{o}}\right)$ for Yola are presented in Figure 1 which shows the variation of the clearness index, a measure of the attenuation of the extraterrestrial global radiation in passing through the turbulent atmosphere before reaching the ground surface. Figure 2 shows the variation of the measured and predicted solar radiation during the year. From the regression analysis the following correlation was found to adequately fit the radiation data presented in Table 1, the values of the regression coefficients $a$ and $b$ as 0.34 and 0.42 .

The statistical error estimations such as RMSE and MBE used to test the correlation between the measured global solar radiation and the calculated global solar radiation. The RMSE was found to be 0.05 as low as expected and the MBE was also found to be 0.015 . Global radiations obtained in this study are higher with mean value of 23.60 $\mathrm{MJm}^{-2}$ and the measured value $23.48 \mathrm{MJm}^{-2}$ which shows the presence of high global solar energy potential in Maiduguri, Nigeria. According to Offiong, (2003) reports that an average solar radiation for Nigeria per month needs to be as high as $20 \mathrm{MJm}^{-2}$ depending on the time of the year which required for which is within the threshold for which Photovoltaic cell can be used to generate electricity. In line with world concern about the economic importance of global solar radiation as an alternative renewable energy, the models for estimating monthly global solar radiation of Maiduguri, Nigeria have been developed to be: $\frac{\bar{H}_{m}}{\bar{H}_{o}}=0.34+0.42 \frac{\bar{S}}{\bar{S}_{o}}$

The estimated global solar radiation data and its correlation will provide a useful source of information to designers of renewable energy, air conditioning systems and other solar energy related systems.

\section{CONCLUSION}

The Angstrom model developed in this study can also be applied to other cities to predict global solar radiation. The result of this study shows that 
there is greater availability of solar radiation in Maiduguri and also solar energy devices will function successfully throughout the year in the area, hence there is a good global solar radiation potential in Maiduguri location with bright prospects for solar energy utilization. The global solar radiation intensity predicted in this study can also be utilized in design, analysis and performance estimation of solar energy systems, which is gaining significant attention in Nigeria and the world at large.

\section{ACKNOWLEDGEMENT}

The authors wish to express their gratitude to Dr. Abdullahi, M. and the Nigerian Metrological Agency, Abuja office for providing solar radiation data for this work.

\section{REFERENCES}

Akinbami, J. (2001). Renewable Energy Resources and Technologies in Nigeria: Present Situation, Future Prospects and Policy Framework, Mitigation and Adaptation Strategies for Global Change 6, $155-181$.

Angstrom, A., (1924), Solar and Terrestrial Radiation, J. Meteor. Soc., 50: 121-126.

Animalu, A.E.O. and Adekola, S.A. (eds) (2002). Science Toady in Nigeria, The Nigerian Academy of Science, Abuja, 190 - 208.

Cooper, P.I (1969). "The Absorption of Radiation on Solar Stills", Solar Energy, vol. 12, no. 3 , pp $333-346$.

Duffie, J. A. and Beckman, W. A., (1991). Solar Engineering of Thermal Processes, 2nd edition, New York: Wiley.

Eze, C.L. (2004). Alternate Energy Resources, Macmillan Nigeria Publishers Limited, First Edition, 159 - 177.

Ilenikhena, P.A. and Mordi, P.C. (2005). Radiation Characteristics of Polished and Solution Grown Iron Pyrite Films on Ferritic Stainless Steel 430 for Solar Energy Application, Nig. Jour. of Solar Energy, $15,187-192$.

Ilenikhena, P.A., Harding, E.E. and Chiedu, J.A. (2008). Thermal Emittance Properties of Polished and Solution Grown Cobalt Sulphide (CoS) Thin Films on Stainless
Steel 430 for Solar Energy Collection, Nig. Jour. of Solar Energy, 19(1), 1 - 5.

Ileoje, O.C. (1997) Potentials for Renewable Energy Application in Nigeria, Energy Commission of Nigeria, $5-16$.

Medugu, D.W, and Malgwi, D.I., (2005). A study of Energy Potential: Remedy for Fluctuation ofElectric Power in Mubi, Adamawa State, Nigeria. Nigeria Journal of physics. 17:40-45.

Neuwirth, F., (1980). The estimation of global and sky radiation in Austria. Sol. Energy 24, $421-426$.

Nguyen, B.T. and Pryor, T. L. (1997): The relationship between global solar radiation and sunshine duration in Vietnam. Renewable Energy, II, 47 (60).

Nwoke, O.O, Okonkwo, W.I. and Oparaku, O.U. (2008). Solar Energy use in Nigeria: Constrains and Possible Solutions, Nig. Jour. of Solar Energy, 19(1), 90 - 93.

Offiong A. (2003). Assessing the economic and environmental prospects of stand-by solar powered system. Nigerian Journal of Applied Science and Environmental Management. 2003; 7(1); 37-42.

Okeke, C.E. (2002). Activities at a Glance, The Presidency Energy Commission of Nigeria, National Centre for Energy Research and Development, University of Nigeria, Nsukka, 3 - 5 .

Onyebuchi, E.I. (1989). Alternative Energy Strategies for the Developing World's Domestic Use: A Case Study of Nigeria Household's Final Use Patterns and Preferences, Energy Journal, 10(3), 121 138.

Oparaku, O.U. (2007). Activities at a Glance, Energy Commission of Nigeria, National Centre for Energy Research and Development University of Nigeria, Nsukka, 7 - 20.

Prescott, J.A., (1940). Evaporation from a water surface in relation to solar radiation. Trans. R. Soc. Sci. Australia 64, $114-$ 125.

Tiwari, R.F and Sangeeta, T.H. (1997): Solar Energy. 24(6) pp. 89 - 95. 